\title{
The influence of surface morphology and wettability on the inflammatory response against poly(L-lactic acid): A semi-quantitative study with monoclonal antibodies
}

\author{
K. H. Lam, ${ }^{1}$ J. M. Schakenraad ${ }^{2, *}{ }^{*}$ H. Groen, ${ }^{1}$ H. Esselbrugge, ${ }^{3}$ P. J. Dijkstra, ${ }^{3}$ J. Feijen, ${ }^{3}$ and \\ P. Nieuwenhuis ${ }^{1}$ \\ ${ }^{1}$ Department of Histology and Cell Biology, Section Biomaterials, University of Groningen, Oostersingel 69-1, 9713 \\ EZ Groningen, The Netherlands; ${ }^{2}$ Biomedical Technology Centre, University of Groningen, Bloemsingel 10, $9712 \mathrm{KZ}$ \\ Groningen, The Netherlands; ${ }^{3}$ Department of Chemical Technology, University of Twente, PO Box 217, 7500 AE \\ Enschede, The Netherlands
}

\begin{abstract}
In this study, the influence of surface morphology and wettability of both degradable and nondegradable polymer films on the inflammatory response after subcutaneous implantation in the rat was investigated. Degradable nonporous, porous, and "combi" (porous with a nonporous layer on one side) poly(L-lactic acid) (PLLA) films and nondegradable polytetrafluoroethylene (PTFE) and (porous) expanded PTFE (e-PTFE) were used. Contact angles measurements indicate that PLLA is more hydrophillic than PTFE. Assessment of the inflammatory response was performed after various periods of implantation (up till 180 days), with both conventional light microscopy and immunohistochemistry using monoclonal antibodies (mAbs). The inflammatory response observed initially can largely be considered as part of the wound healing reaction, and up till day 40 the inflammatory response against PLLA was minimally more intense than against PTFE (porous as well as nonporous). From day 40 on, the PLLA films provoke a
\end{abstract}

more intense inflammatory response as compared to the PTFE films. Both porous PLLA and the porous side of the "combi" PLLA film provoke a more intense inflammatory response than nonporous PLLA and the nonporous side of the "combi" PLLA film, respectively. In general, PTFE and e-PTFE films provoke an inflammatory response which is minimally more intense than the one provoked by the sham operation. Almost no ingrowth of tissue was observed in the porous e-PTFE films. In contrast, there was abundant tissue ingrowth in and an inflammatory response against porous PLLA. It can be concluded that biodegradable PLLA films provoke a more intense inflammatory response than nondegradable PTFE films. Also, porosity enhances the inflammatory response. However, porosity enhances the inflammatory response only when the wettability of a biomaterial permits cellular ingrowth. C) 1995 John Wiley \& Sons, Inc.

\section{INTRODUCTION}

Upon implantation of polymers, local ${ }^{1,2}$ and systemic ${ }^{3}$ effects can be observed. The local tissue reaction consists of an inflammatory response which serves to eliminate the cause of an injury, minimize the damage, and trigger mechanisms for repairing the tissue damaged by injury. The surgical procedure initially determines the type and intensity of the inflammatory response. However, in addition, implanted polymers themselves provoke an inflammatory response. ${ }^{2}$ The characterization of and research on the factors determining this response can lead to new strategies for minimizing the inflammatory response against implanted polymers.

*To whom correspondence should be addressed.
Surface morphology is one of the factors influencing the inflammatory response against the biomaterial. This is indicated in various studies. ${ }^{4,5}$ Matlaga et al. demonstrated the role of shape. ${ }^{6}$ The intensity of the inflammatory response increases when the number of edges of the implanted materials increases. Also, there are studies indicating that the inflammatory response against implanted porous polymers or biomaterials is more intense when compared to nonporous materials. $^{7}$

Wettability may influence the tissue reaction to the polymer, because there is a range in wettability values that is optimal for cell adhesion, growth, and spreading. Cells attach and proliferate less well on polymers having a wettability which is too $\operatorname{low}^{8}$ or too high. ${ }^{9}$

Another factor is degradability. Degrading polymers 
provoke a more intense inflammatory response compared to nondegrading polymers. A possible cause for this observation may be the release of monomers, oligomers, and/or fragments upon degradation. ${ }^{10,11}$ However, at earlier stages of the degradation process, changes (such as an increase) in the surface morphology of a polymer (film) may occur, which in turn may alter the inflammatory response.

In this paper, the (combined) influence of these factors were studied. Therefore, degradable and nondegradable polymer films, having a different porosity and wettability, were implanted subcutaneously in the back of the rat and the tissue reaction against them was evaluated. As biodegradable polymer, poly(L-lactic acid) (PLLA) was chosen because it has many (potential) uses. ${ }^{11-13}$ As nondegradable, more hydrophobic polymer, nonporous and porous polytetrafluoroethylene (PTFE and e-PTFE, respectively) were chosen because polytetrafluoroethylene is considered to be biologically inert and nondegradable. ${ }^{14,15}$

The inflammatory response was characterized using semi-quantitative techniques comprising morphological criteria and monoclonal antibodies directed against epitopes which are specific for the respective cell types.

\section{MATERIALS AND METHODS}

\section{Materials}

Poly(L-lactic acid) films were cast from PLLA with a reported Mv of 50,000 (Purac Biochem B.V., The Netherlands). ${ }^{16}$ Three types of films were cast: a nonporous type, a porous type, and a "combi" type (porous with a nonporous layer on one side), according to procedures described previously. ${ }^{17}$ The base parameters of the PLLA films are listed in Table I. All PLLA films were cut in strips of $15 \times 2 \mathrm{~mm}$.

Polytetrafluoroethylene (PTFE) was obtained commercially (Wientjes, The Netherlands). PTFE was cut into strips of $15 \times 2 \times 1 \mathrm{~mm}$.

Expanded polytetrafluoroethylene (e-PTFE) was

TABLE I

Base Parameters of the PLLA Films

\begin{tabular}{lccc}
\hline Parameter & $\begin{array}{c}\text { Nonporous } \\
\text { PLLA film }\end{array}$ & $\begin{array}{c}\text { Porous } \\
\text { PLLA film }\end{array}$ & $\begin{array}{c}\text { Combi } \\
\text { PLLA film }\end{array}$ \\
\hline $\mathrm{Mw}$ & 98,000 & 109,000 & 167,000 \\
$\mathrm{Mn}$ & 42,000 & 41,000 & 53,000 \\
$\mathrm{Mw} / \mathrm{Mn}$ & 2.3 & 2.7 & 3.1 \\
Tm & $176^{\circ} \mathrm{C}$ & $180^{\circ} \mathrm{C}$ & $181^{\circ} \mathrm{C}$ \\
Heat of fusion & $53 \mathrm{~J} / \mathrm{g}$ & $51 \mathrm{~J} / \mathrm{g}$ & $50 \mathrm{~J} / \mathrm{g}$ \\
\hline
\end{tabular}

obtained as nonsterile GORE-TEX ${ }^{\mathrm{R}}$ e-PTFE cell collector tubing (WL Gore \& Associates GMBH, Germany). The tubing was cut open along the longitudinal axis to obtain films measuring $15 \times 2 \times 0.25 \mathrm{~mm}$.

Except for PTFE, the final thickness of the films was determined with scanning electron microscopy (SEM). All films were cleaned by washing in a phosphate buffered saline (PBS) for $24 \mathrm{~h}$ prior to use.

\section{Surface morphology}

Specimens of all films were sputter-coated with gold (Balzers 07 120B) and their surface morphology was examined with a DS 130 scanning electron microscope (SEM) (ISI), operated at $10 \mathrm{kV}$.

\section{Wettability}

Wettability was determined by contact angle measurements using the sessile drop technique described by Busscher et al. ${ }^{18}$ For PTFE and the nonporous PLLA, the contact angles were determined using $\mathrm{H}_{2} \mathrm{O}$ and $\alpha$-bromonaphthalene as wetting agents. Five measurements were made for each polymer and wetting agent.

\section{Cytotoxicity}

To detect possible cytotoxicity prior to implantation, films were tested in a direct contact test using a human skin fibroblasts cell line. The fibroblasts were cultured in $25 \mathrm{~cm}^{2}$ T-Flasks (Greiner, The Netherlands) using RPMI 1640 medium (Gibco Europe B.V., The Netherlands) supplemented with $15 \%$ fetal calf serum (Gibco) and $100 \mathrm{IU} / \mathrm{ml}$ penicillin/streptomycin (Sigma) (Brunswick, The Netherlands) in humidified air with $5 \% \mathrm{CO}_{2}$ at $37^{\circ} \mathrm{C}$. Every two days, the cultures were subdivided, using trypsin $0.05 \%$ in $\mathrm{Ca}^{2+} / \mathrm{Mg}^{2+}$ free phosphate buffered saline (PBS).

The films were disinfected by immersion in ethanol $70 \%$ for $1 \mathrm{~min}$ and air-dried under sterile conditions in a laminar flow cabinet. Subsequently, polymer films were mounted on the bottom of a well of a six well tissue culture polystyrene plate (Greiner). Three $\mathrm{mL}$ medium, containing approximately $5.10^{4}$ cells, was added to each well. One well without polymer film (tissue culture polystyrene) served as a negative control. The medium was changed every fourth day.

Cell cultures were evaluated qualitatively for signs of cell lysis, formation of an inhibition zone, and/or change in cell morphology for up till 12 days. 


\section{Implantation procedure}

The films were disinfected as described above prior to implantation and implanted subcutaneously in 21 female $(A O x B N) F_{1}$ rats obtained from our own breeding facility. The films were implanted according to procedures described previously. ${ }^{16}$ In each rat a nonporous PLLA film, a porous PLLA film, a "combi" PLLA film, PTFE film, and an e-PTFE film were implanted. The sixth incision and subcutaneous pocket served as a control (sham operation). Three samples per polymer and time interval were implanted. The rats had free access to standard rat food and water. All national rules concerning the care and use of laboratory animals have been observed.

The rats were sacrificed after $1,3,7,14,40,90$, or 180 days and the polymer films were removed with excess surrounding tissue.

\section{Evaluation of the inflammatory response}

\section{Light microscopy}

After harvesting, the samples were immediately fixed for at least $24 \mathrm{~h}$ at $4^{\circ} \mathrm{C}$ in a $0.1 \mathrm{M} \mathrm{Na}$-cacodylate buffer, pH 7.4, containing 2\% glutaraldehyde and 0.1 $M$ sucrose. The samples were then dehydrated in a graded ethanol series and embedded in glycolmethacrylate (Technovit ${ }^{\circledR}$, Kulzer, Germany), allowing sections to be cut perpendicular to the longitudinal axis of the polymer film. Sections for lightmicroscopical examination were cut on a microtome (Jung autocut 1140 , equipped with a D knife with a tung- sten carbide cutting edge), mounted on glass slides, and stained with toluidine blue and alkaline fuchsin. ${ }^{19}$

Immunohistochemical staining

After harvesting, samples were snap-frozen at $-80^{\circ} \mathrm{C}$ using liquid freon. Cryostat sections of $7 \mu \mathrm{m}$ were cut, mounted on glass slides, air-dried, and fixed in acetone for $12 \mathrm{~min}$. The sections were then again air-dried for $1 \mathrm{~h}$ and incubated with the firststage, cell type specific, monoclonal antibody (mAb) for $1 \mathrm{~h}$. Subsequently, the sections were washed 3 times in PBS, followed by incubation with the second-stage antibody conjugated to peroxidase, diluted 1:40 in PBS, and supplemented with $5 \% \mathrm{v} / \mathrm{v}$ normal rat serum to prevent nonspecific binding. Swine antirabbit Ig (Dakopatts, Denmark) was used as secondstage antibody to detect the first-stage mAb $\alpha$-Asialo $\mathrm{GM}_{1}$ (Table II). Rabbit anti-mouse Ig (Dakopatts, Denmark) was used to detect the other first-stage mAbs. After incubation with the second-stage antibody, sections were rinsed 3 times in PBS for $5 \mathrm{~min}$. Peroxidase activity was demonstrated by applying 3,3-diaminobenzidine tetrahydrochloride (Sigma) at a concentration of $0.5 \mathrm{mg} / \mathrm{mL}$ in $0.05 \mathrm{M}$ Tris- $\mathrm{HCl}$ buffer (pH 7.6) containing $0.01 \% \mathrm{H}_{2} \mathrm{O}_{2}$ for $10 \mathrm{~min}$. After rinsing in fresh tap water, sections were counterstained lightly with haematoxylin for $10 \mathrm{~s}$. The sections were then dehydrated using a graded ethanol series and xylene and subsequently covered with coverslips using DePeX (Gurr, BDH Ltd, England) mounting medium. In controls, PBS was used instead of the first-stage mAb. The first-stage mAbs used and their sources are shown in Table II.

TABLE II

Monoclonal Antibodies (mAbs) Used to Examine and Quantify the Inflammatory Response Against the Implanted Polymer Films ${ }^{a}$

\begin{tabular}{|c|c|c|c|}
\hline $\begin{array}{l}\text { Monoclonal } \\
\text { Antibody }\end{array}$ & Epitope & $\begin{array}{l}\text { Mainly Characterizing Cell Type in } \\
\text { Subcutaneous Tissue: }\end{array}$ & Ref. No. \\
\hline $\mathrm{OX} 1$ & $\mathrm{CD} 45$ & All leucocytes & 20 \\
\hline HIS 48 & Probably surface antigen & Granulocytes & 21 \\
\hline OX 19 & CD 5 & T-lymphocytes & 22 \\
\hline HIS 40 & IgM heavy chain & $\begin{array}{l}\text { B-lymphocyte subset likely to react first upon inflammatory } \\
\text { response }\end{array}$ & 23 \\
\hline ED 1 & Lysosomal antigen & $\begin{array}{l}\text { Majority of macrophages. Probably associated with active } \\
\text { phagocytosis. }\end{array}$ & 24 \\
\hline ED 2 & Surface antigen & Subset macrophages. Probably associated with maturity. & 24,25 \\
\hline ED 3 & Surface antigen & $\begin{array}{l}\text { Subset macrophages. Probably associated with } \\
\text { downregulation of inflammatory reaction }\end{array}$ & 24,26 \\
\hline$\alpha$-Asialo GM1 & Probably surface antigen & Large granular lymphocytes/natural killer cells & 27 \\
\hline HIS 19 & MHC class II & Activated tissue cells (fibroblast) IDC, Subset macrophage & 28 \\
\hline
\end{tabular}

aSource of the mAbs: OX antibodies were a generous gift of the late Dr. A. F. Williams, Department of Biochemistry, University of Oxford, Great Britain; ED antibodies were a generous gift of Dr. C. D. Dijkstra, Department of Cell Biology, Free University Amsterdam, The Netherlands; HIS antibodies were made at our Department of Histology and Cell Biology and the Asialo antibody was obtained at BAKO, The Netherlands. 
Quantification of the inflammatory response

The magnification of the light microscope was set at $400 \times$ when examining the sections stained using mAbs. The staining patterns of the tissue surrounding or invading the polymer film was evaluated and the number of positive cells surrounding or invading the polymer films per field of view counted. Four fields of view per section, two sections per sample and three samples for each period of implantation, polymer film and monoclonal antibody, respectively, were examined. The tissue reaction at the edges of the polymer films were excluded from evaluation, to avoid artifacts due to mechanical irritation.
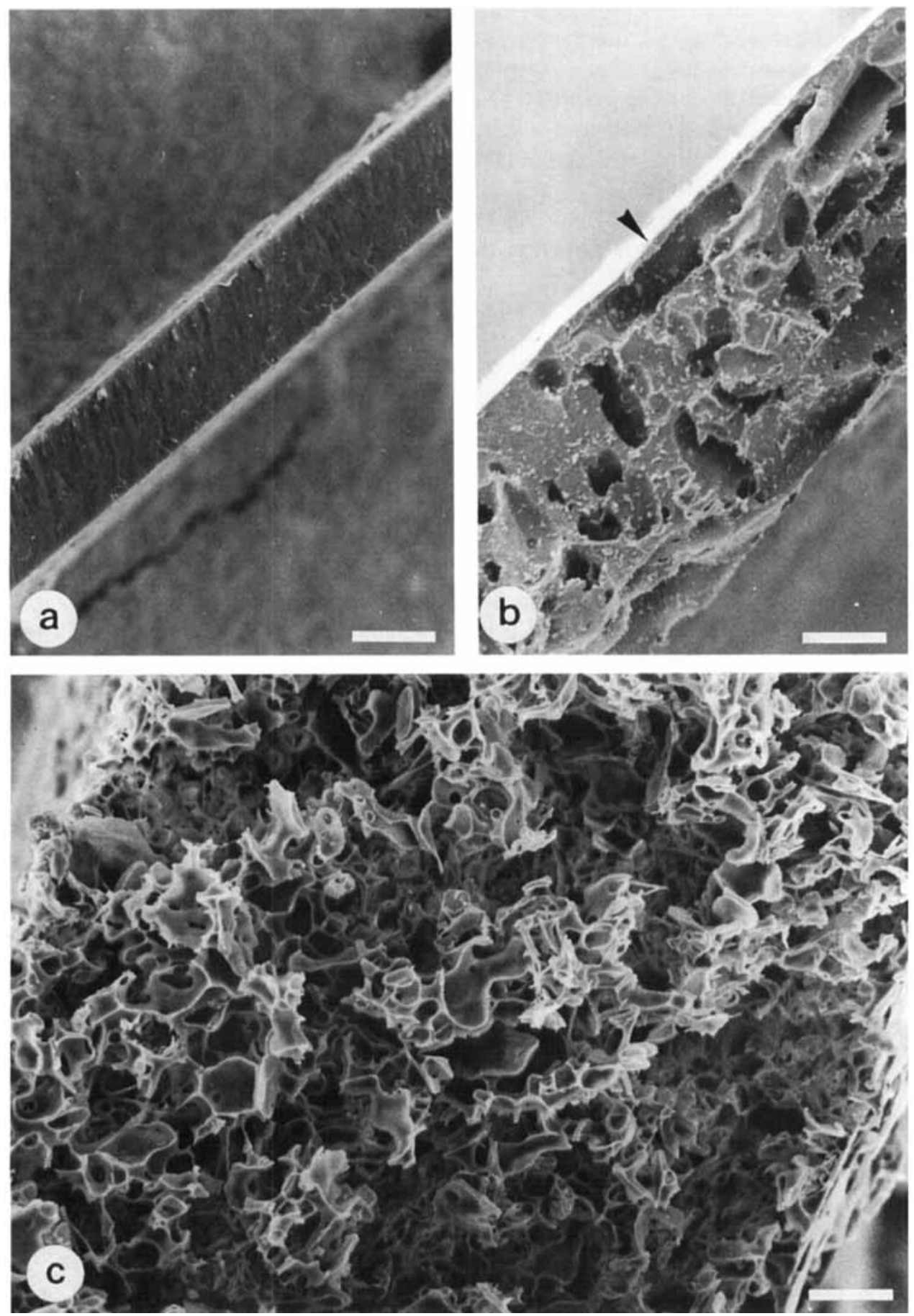

Figure 1. Scanning electron micrographs of a cross-section of PLLA films. (A) nonporous, (B) "combi" (arrow head indicates the nonporous side), (C) porous. The thickness of the films is: nonporous, $33 \mu \mathrm{m}$, porous, $244 \mu \mathrm{m}$, and "combi," $82 \mu \mathrm{m}$. The thickness of the nonporous layer of the "combi" film was approximately $5 \mu \mathrm{m}$. The pore size of the porous film varied from approximately 1 to $150 \mu \mathrm{m}$ and of the "combi" film from 1 to $50 \mu \mathrm{m}$. Bar indicates $22 \mu \mathrm{m}$. 
The number of cells staining positively per field of view was classified as follows:

grade $0=$ no positive cells,

$1=1$ to 5 positive cells per field of view,

$2=5$ to 10 positive cells per field of view,

$3=10$ to 25 positive cells per field of view, and

$4=$ more than 25 positive cells per field of view.

The average class of the 24 fields of view for each period of implantation, polymer film and monoclonal antibody, respectively, is reported.

\section{RESULTS}

\section{Surface morphology}

The thickness of the polymers was calculated using SEM: nonporous: $33 \mu \mathrm{m}$ [Fig. 1(A)], porous: $244 \mu \mathrm{m}$ [Fig. 1(C)] and the "combi" film: $82 \mu \mathrm{m}$ [Fig. 1(C)]. The nonporous layer of the "combi" film was approximately $5 \mu \mathrm{m}$. The pore size of the porous film varied from approximately 1 to $150 \mu \mathrm{m}$ and of the "combi" film from 1 to $50 \mu \mathrm{m}$. PTFE was nonporous, having the same morphological appearance of the surface as the nonporous PLLA film. The thickness of the porous e-PTFE film was approximately $250 \mu \mathrm{m}$, with a fibril length of approximately $90 \mu \mathrm{m}$ (Fig. 2).

\section{Wettability}

The highest value of each set of five measurements is maximally 5 degrees higher than the lowest value. Therefore, it was not relevant to determine the standard deviation. The $\mathrm{H}_{2} \mathrm{O}$ contact angles were $101^{\circ}$ for PTFE and $72^{\circ}$ for nonporous PLLA, and the $\alpha$-bromonaphthalene contact angles were $66^{\circ}$ for PTFE and $23^{\circ}$ for nonporous PLLA. This shows that nonporous PLLA has a less hydrophobic surface than PTFE.

\section{Cytotoxicity}

Neither cell death, nor the formation of cell growth inhibition zones were observed. The morphological appearance of the fibroblasts in all wells in which materials were tested was normal and not differing from the controls. Thus, there was probably no release of large quantities of toxic products up till the end of the experiment at day 12 .

\section{Evaluation of the inflammatory response}

Macroscopically, there were no signs of an infection demonstrated by any of the rats. The results of



Figure 2. Scanning electron micrograph of (porous) ePTFE. The fibril length (= distance between A and B) is approximately $90 \mu \mathrm{m}$. Bar indicates $30 \mu \mathrm{m}$. 
the semi-quantitative evaluation of the immunohistochemical staining to detect leucocytes (OX 1), neutrophilic granulocytes (HIS 48), macrophages (ED 1, ED 2, ED 3), T-lymphocytes (OX 19), vast majority of B-lymphocyte (HIS 40), natural killer cells ( $\alpha$-asialo $\mathrm{GM}_{1}$ ), cells expressing MHC class II antigen, such as activated fibroblasts (His 19) are demonstrated in Figures 3(A) to (I), respectively. False positive cells were observed occasionally in PBS controls. This was due to endogenous peroxidase activity expressed only by neutrophilic granulocytes, since the staining pattern using HIS 48 corresponds with the pattern of endogenous peroxidase activity. Moreover, cells expressing endogenous peroxidase activity can be well distinguished, due to their more intense staining as compared to cells stained for mAbs.

The concentration of B-lymphocytes [Fig. 3(D)] and the concentration of natural killer cells [Fig. $3(\mathrm{H})$ ] was



a ALL LEUCOCYTES (OX 1)

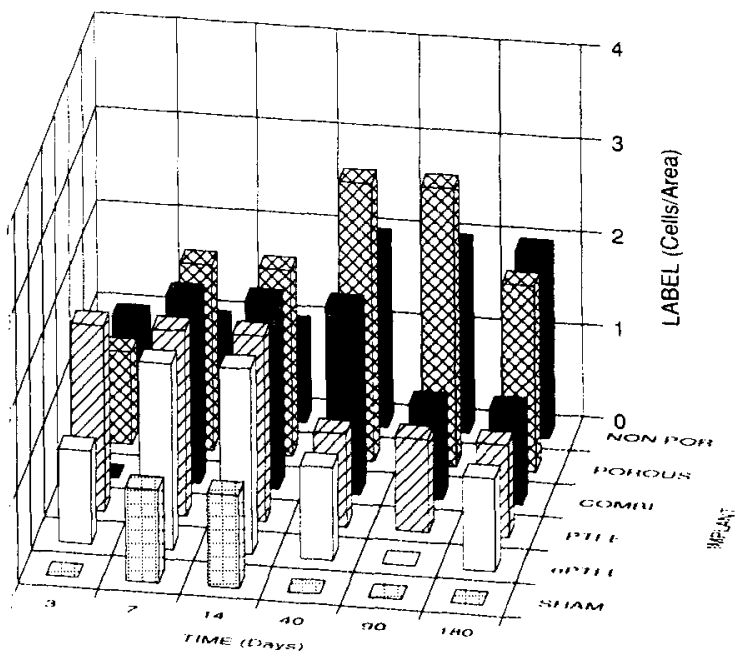

C T-LYMPHOCYTES (OX 19)

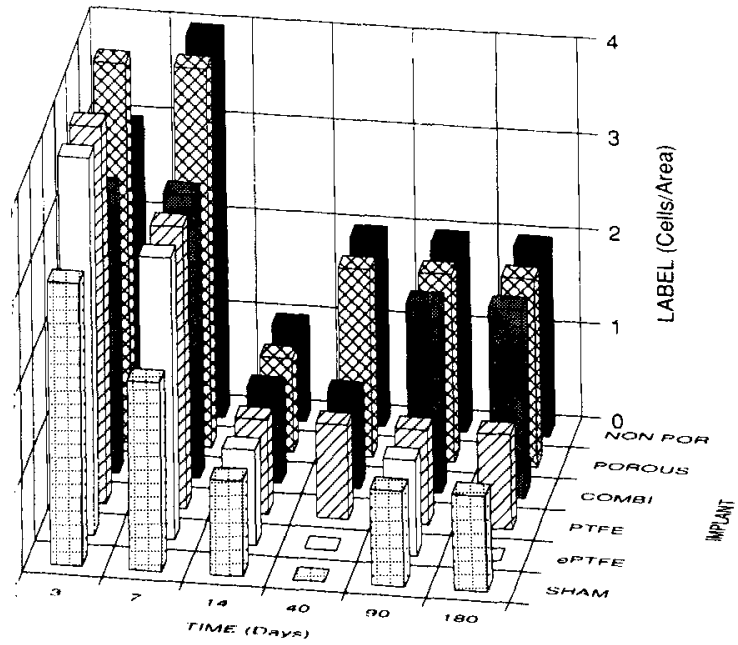

b NEUTROPHILS (HIS 48)



B-LYMPHOCYTES (HIS 40)

Figure 3. The average class of 24 fields of view of the number of cells involved in the inflammatory response against the implanted polymer films, stained with different $\mathrm{mAbs}$. Class criteria: grade $0=$ no positive cells, grade $1=1$ to 5 positive cells, grade $2=5$ to 10 positive cells, grade $3=10$ to 25 positive cells and grade $4=$ more than 25 positive cells per field of view at an original magnification of $400 \times$. The following mAbs were used: (A) OX 1, all leucocytes, (B) HIS 48, neutrophilic granulocytes, (C) OX 19, T-lymphocytes, (D) HIS 40, vast majority of B lymphocytes, (E) ED 1, vast majority of macrophages, including multinuclear giant cells, (F) ED 2, subset (mature/resident) macrophages, (G) ED 3, subset macrophages, (H) $\alpha$-Asialo $\mathrm{GM}_{1}$, natural killer cells/large granular lymphocytes, (I) HIS 19, cells expressing MHC II antigen, e.g., activated fibroblasts, macrophages, dendritic cells. X-axis represents implantation time (days). Y-axis the average number of cells per field of view as class 0 to 4 . Z-axis represents the different polymer films. 

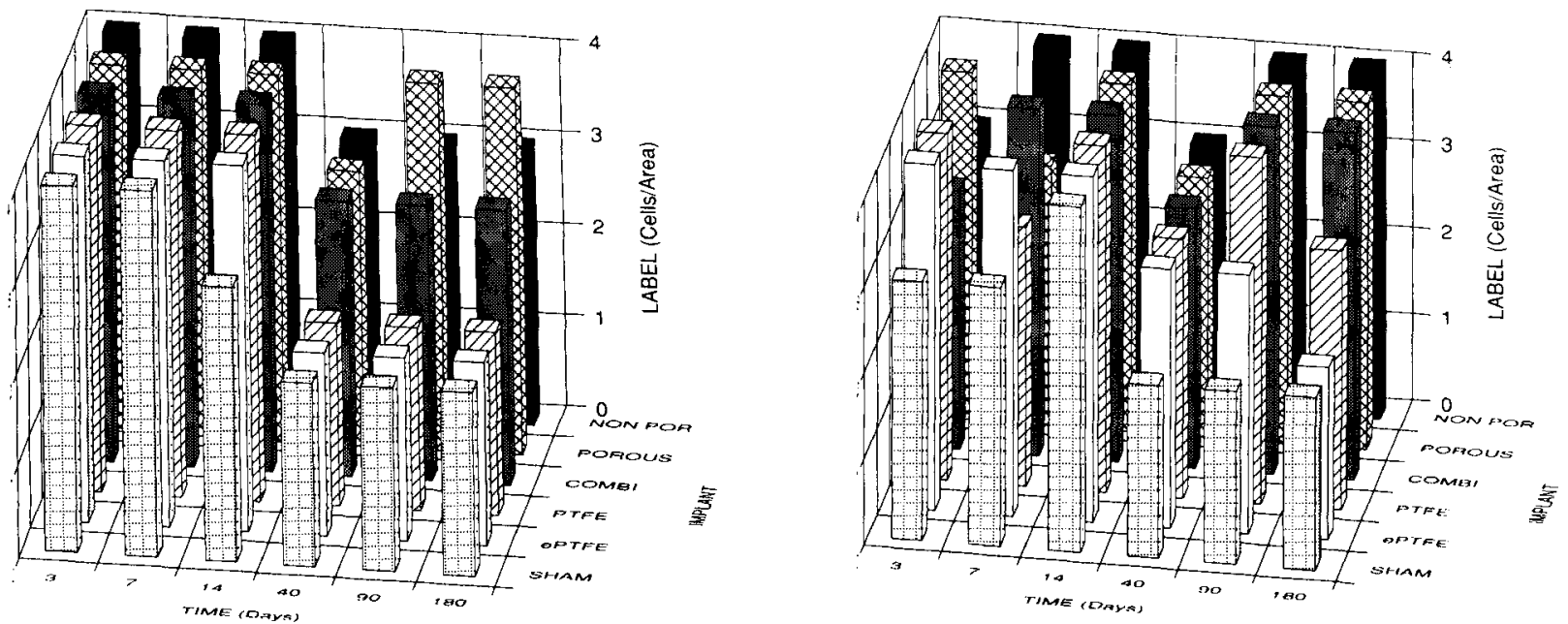

e MACROPHAGES (ED 1)

$f$ MACROPHAGES (ED 2)

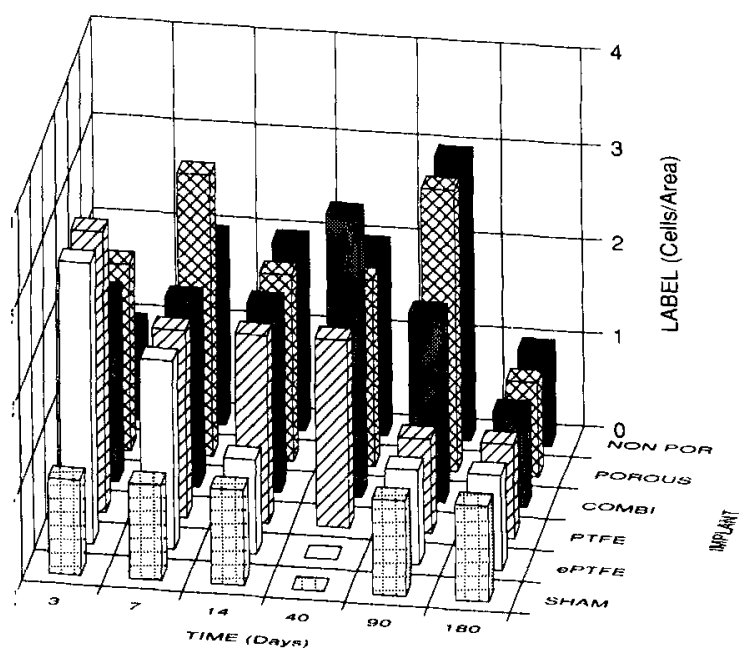

9 MACROPHAGES (ED 3)
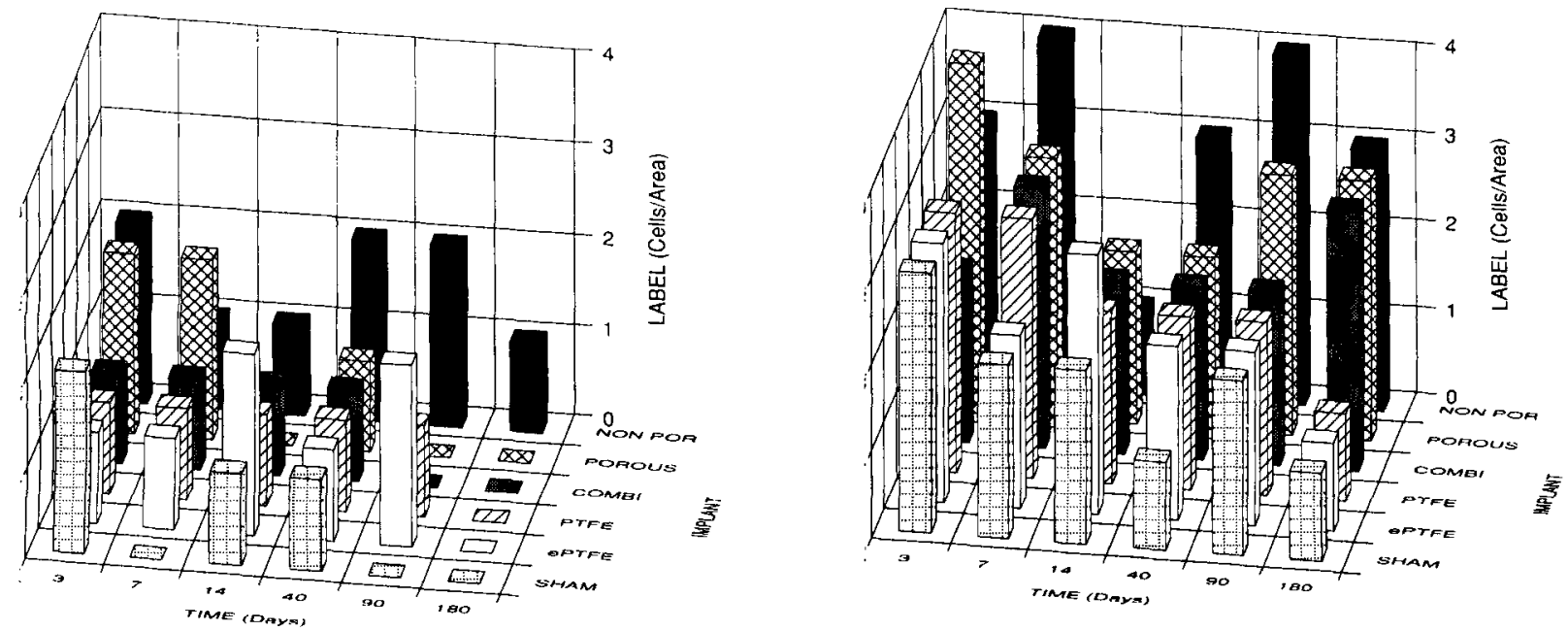

h NKCELLS (ASIALO)

MHC II ANTIGEN (HIS 19)

Figure 3. Continued 
to a large extent similar and low for both PLLA, PTFE films, and the subcutaneous tissue under the scar of the sham operation.

At day 3, the concentration of each cell type involved in the inflammatory response as a measure for the intensity was approximately the same for all the polymers films [Fig. 3(A) to (G)].

At day 7 , macrophages are beginning to play a prominent role in the inflammatory response [Fig. $3(E)]$. Subsets of macrophages surrounding the polymer films were found in different locations. ED 1 positive macrophages are found in the entire area demonstrating inflammatory response against the implant, especially in the area in closest approximation of the polymer film [Fig. 4(A)]. In contrast, ED 2 and ED 3 positive macrophages are neither found in the area in closest approximation the polymer film, nor in the pores of the PLLA or PTFE film. ED 2 and ED 3 positive macrophages remain restricted to the surrounding tissue at some distance from the implant [Fig. 4(B) and (C)]. The relative ratio between the subsets was fairly constant for the respective implants.

In GMA sections it is observed that the inflammatory response at day 7 is becoming more intense for the porous PLLA and porous side of the "combi" PLLA films (Fig. 5). For the nonporous PLLA and the nonporous side of the "combi" PLLA film, the onset of encapsulation by approximately 3 layers of fibroblasts was observed. Only a minimal encapsulation is observed for the porous PLLA film at day 7.

In contrast to the porous PLLA film almost no cellular invasion of the e-PTFE film was observed. The cell layer surrounding e-PTFE consists mainly of macrophages. The PTFE film was surrounded by one or two layers of macrophages and the onset of encapsulation can be observed.

At day 14 , the inflammatory response becomes chronic with predominantly macrophages and T-lymphocytes surrounding the films. In GMA sections, foreign body giant cells can be observed surrounding the PLLA films (Fig. 6). All films are now encapsulated by continuous layers of fibrocytes and collagen. The fibrocytes are not stained by HIS 19 monoclonal antibody, indicating a decrease in cell activity.

The porous PLLA film and porous side of the "combi" film provokes a more intense inflammatory response than the nonporous PLLA film and nonporous side of the "combi" film, respectively. However, this observation could not be made for the e-PTFE film as compared to the PTFE film.

At day 40, in general, the intensity of the inflammatory response against the polymer films had decreased further. However, PLLA films still provoke a more intense inflammatory response than PTFE films as demonstrated by the higher concentration of neutrophils, macrophages/giant cells, and T-lymphocytes surrounding the PLLA films [Fig. 3(B), (C), (E), (F), and $(\mathrm{G})]$. The concentration of cells against PTFE and e-PTFE films is comparable to the concentration of cells in the subcutaneous tissue under the scar of the sham operation.

The inflammatory response against the nonporous PLLA film was mainly localized at the edges of the film or at the edges of the pieces when broken. In contrast, the inflammatory response against porous PLLA films was localized in the pores. The "combi" film shows a more pronounced inflammatory response at the porous side.

At day 90 , the difference in the intensity of the inflammatory response between PLLA and PTFE films and also between nonporous and porous PLLA films had become much more pronounced. This is demonstrated by the increased concentration of macrophages, leucocytes, and cells expressing MHC class II (HIS 19) antigen, (probably activated fibroblasts) surrounding or invading the PLLA films. The porous PLLA films provokes a more intense inflammatory response than the nonporous PLLA film. In contrast, the inflammatory response against PTFE and e-PTFE films remained the same as at day 40 .

At day 180, the difference in the intensity of the inflammatory response between the nonporous and porous PLLA film was more pronounced. In contrast, the tissue reaction ("inflammatory response") against PTFE and e-PTFE did not differ much from the tissue reaction in the subcutaneous tissue under the scar of the sham operation. There are almost no cells localized in the pores of e-PTFE (Fig. 7). In contrast, the inflammatory response against porous PLLA was localized in mainly the large pores.

\section{DISCUSSION}

\section{Inflammatory response and biocompatibility}

The results demonstrate that there are two phases in the inflammatory response against the films. Phase 1 is observed upon implantation of the film. It is mainly caused by the injury sustained by the implantation procedure. This uncomplicated inflammatory response, part of the wound healing reaction, ends after 7 to 10 days and has been well described. ${ }^{2,29}$ In this phase, the contribution of the implanted polymer film to the intensity of the inflammatory response is in most cases minimal, except when leakage of large quantities of toxic products occurs. ${ }^{30}$ After one week, any remaining inflammatory response can be considered as a tissue reaction against the implanted biomaterial. ${ }^{31}$ This chronic inflammatory response (phase 2) is often described as a foreign body reaction. ${ }^{1,2,31}$ It mainly consists of macrophages and giant cells surrounding the implant. 

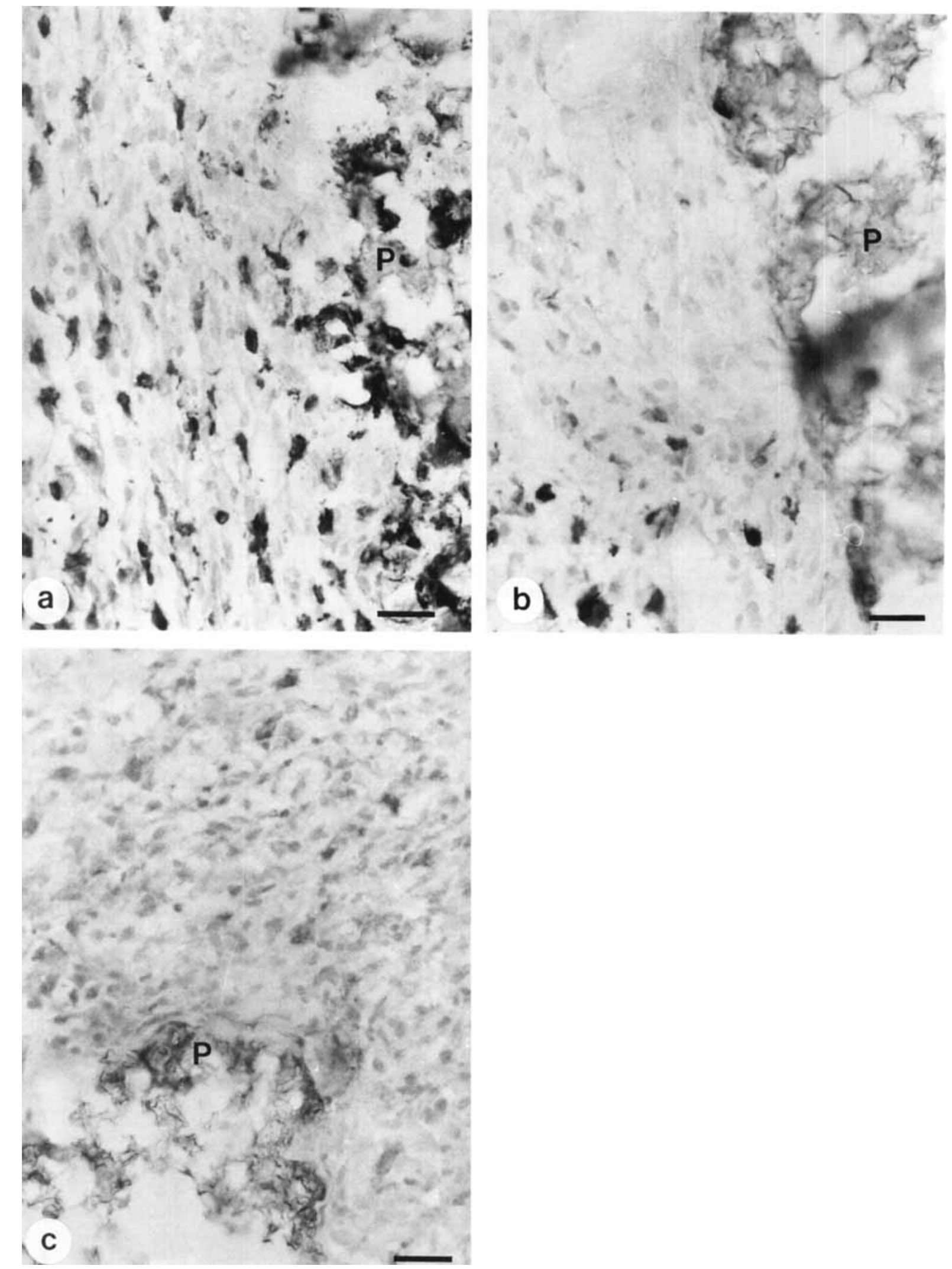

Figure 4. Immunohistochemical staining of the tissue surrounding the porous PLLA film (P) at day 7, with: (A) ED 1. The macrophages adjacent to the implant stain positive for ED 1. No ED 1 positive cells are observed in the polymer film. (B) ED 2. The macrophages adjacent to the implant do not stain positive for ED 2. The cells in the left lower corner stain false positive for ED 2. This is due to endogenous peroxidase activity of neutrophilic granulocytes. (C) ED 3. The macrophages adjacent to the implant do not stain positive for ED 3. Bar indicates $40 \mu \mathrm{m}$. 


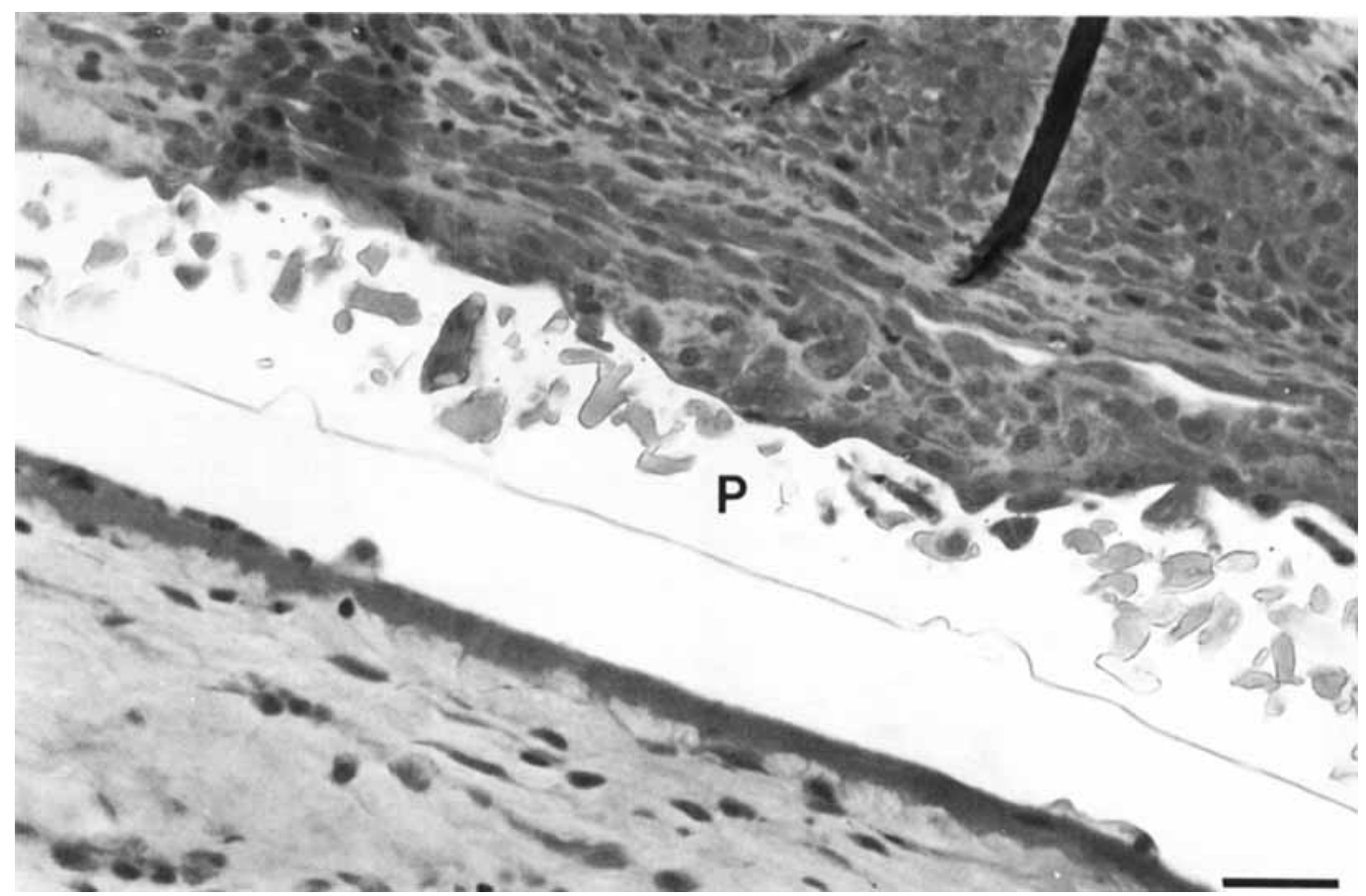

Figure 5. "Combi" PLLA film (P) 7 days after implantation. Note the difference in the intensity of the inflammatory response between the porous and nonporous side. Bar indicates $40 \mu \mathrm{m}$.

A minimal inflammatory response is preferred when biomaterials are implanted for a long time span, because a persistent (chronic) inflammatory response may predispose for amyloidosis ${ }^{32,33}$ or carcinogenesis. ${ }^{34}$ A persistent inflammatory response increases the concentration of both serum amyloid $A$
(SAA) and amyloid enhancing factor (AEF) in blood. SAA may then be converted into amyloid $A$, which is deposited in tissues. ${ }^{32,33}$ However, the exact mechanism is yet to be fully uncovered and the relation between the chronic inflammatory response against biomaterials and amyloidosis also remains to be in-



Figure 6. Nonporous PLLA film (P) 14 days after subcutaneous implantation. Note the large concentration of giant cells (arrow heads). Bar denotes $40 \mu \mathrm{m}$. 

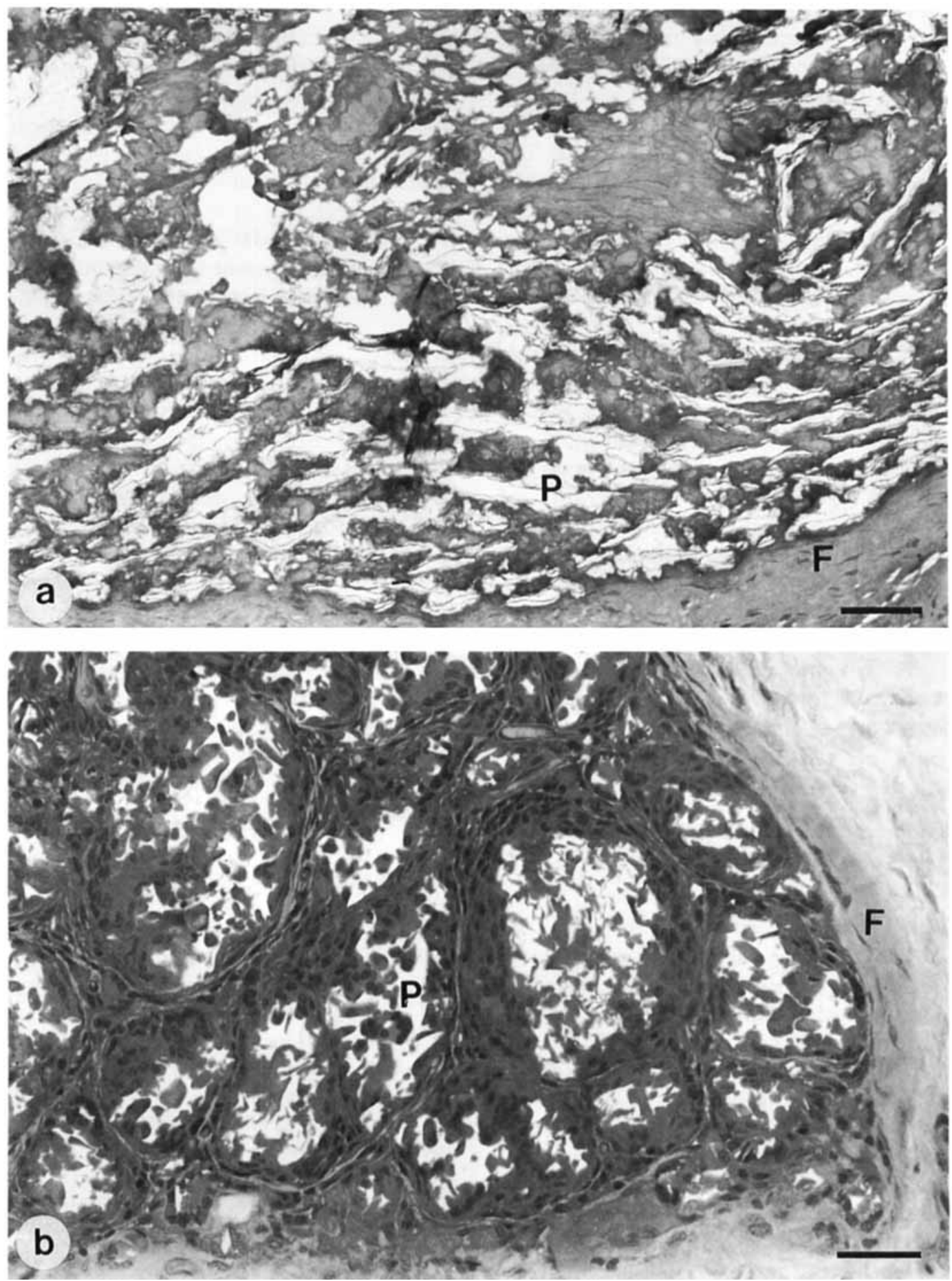

Figure 7. (A) Porous e-PTFE (P) and (B) porous PLLA (P) after 180 days of implantation. There are almost no inflammatory cells localized in the pores of the e-PTFE film. In contrast, the inflammatory response is localized mainly in the large pores of the porous PLLA film. $F=$ fibrous encapsulation. Bar indicates $63 \mu \mathrm{m}$.

vestigated. There are reports demonstrating a higher tumour incidence at the implantation site of PLLA ${ }^{35}$ and other polymers ${ }^{36}$ in rats. However, the authors did not correlate their findings to an inflammatory response as they only indicated stimulation as a possible cause. Therefore, the relation between chronic inflammatory response against polymers and carcinogenesis needs further investigation.
The role of macrophages and giant cells

ED 1 stains an intracellular antigen probably associated with the lysosomal membrane. ${ }^{24}$ The antigen probably remains present, even in the event of fusion of macrophages and formation of foreign body giant cells, since ED 1 positive cells are observed on the same location of foreign body giant cells in conven- 
tional light microscopical sections. ED 2 is a marker which is found on mature tissue macrophages. It takes about one week for monocytes/macrophages to express ED 2 on their cell surface after leaving the vascular system. ${ }^{25}$ The role of ED 2 and ED $3^{26}$ in the inflammatory response is not well understood. The different staining patterns of the ED antibodies indicate the possibility of either different populations of macrophages which play a role in the tissue reaction against biomaterials, or macrophages expressing different surface receptors in the course of the inflammatory response against a biomaterial.

The exact mechanism of foreign body giant cell formation is still to be elucidated. Certain cell types, e.g., T-lymphocytes, may play a pivotal role in this process. Especially T-helper lymphocytes capable of secreting interferon- $\gamma$ may play a role in the fusion of macrophages, forming giant cells. ${ }^{37,38}$ Activation of macrophages may be induced by various pathways. In one pathway, (limited) damage to neutrophils and macrophages may lead to secretion of cytokines (IL1), activating T-helper lymphocytes. Another possibility is change of shape when a macrophage comes in contact with a biomaterial, ${ }^{39,40}$ especially when a single macrophage is not able to phagocytose the polymer (fragment).

\section{Porosity, wettability, degradability, and inflammatory response}

Porous PLLA provokes a more intense inflammatory response from day 7 on, despite a higher degradation rate of the nonporous PLLA in aqueous environment. ${ }^{17}$ This indicates that porosity is an important factor determining the intensity of the inflammatory response against implanted PLLA films. The small difference in the intensity of the inflammatory response between PTFE and e-PTFE as compared to nonporous and porous PLLA, respectively, indicates that porosity as a single factor is not enough to enhance the inflammatory response. The relatively high wettability of PLLA compared to e-PTFE allows for better ingrowth of tissue into the pores of PLLA and probably more exposure to other factors, determining the intensity of the inflammatory response.

According to many authors, the surface properties of an implant have a large influence on the inflammatory response. ${ }^{41-43}$ Thus, the difference in wettability as one of the surface properties may also be a factor, although Baier et al. could not demonstrate a difference in the inflammatory response against smooth metal pieces having a different wettability. ${ }^{44}$ However, other authors demonstrated that different polymers induces a different level of IL-1 production, correlating with the intensity of the inflammatory response, ${ }^{45-47}$ although the relation with wettability was not investigated. However, the production of IL-1 seems to be less when using relatively hydrophobic materials such as silicon. Further investigation is needed to establish the precise relation between wettability and inflammatory response.

The differences in inflammatory response against the PLLA (degradable) and PTFE (nondegradable) films became apparent from day 40 . One reason may be the difference in the rate of degradation and subsequently the difference in the release of degradation products, such as monomers, oligomers, and finally fragments. As stated previously, only a few (mostly nonporous) PLLA films were observed to be broken into two or three pieces. However, there is probably also increase in surface area which could hardly be observed. Also, the size of the pores of the porous PLLA films has increased with possibly the same effect as fragmentation. In the case of PLLA films, the increase in surface area during the degradation process as a single factor may be sufficient for increasing the intensity of the inflammatory response.

It can be concluded that biodegradable PLLA films provoke a more intense inflammatory response than nondegradable PTFE films. Also, porosity enhances the inflammatory response. However, porosity enhances the inflammatory response only when the wettability of a biomaterial permits cellular ingrowth.

The authors acknowledge Dr. C. D. Dijkstra, Dept. Cell Biology, Free University, Amsterdam, for her generous gift of and her expert advice on the interpretation of the results of the ED monoclonal antibodies, the late Dr. A. F. Williams, Department of Biochemistry, University of Oxford, Great Britain for his generous gift of the OX antibodies, Dr. U. Thellmann (WL Gore and Associates GMbH, Germany) for kindly providing the e-PTFE, E. H. Blaauw for the preparation of the lightmicroscopical sections, $W$. Ammerlaan and F. Klatter for their assistance with the immunocytochemistry, F. Dijk and D. Kalicharan for the preparation of the SEM samples, D. Huizinga, H. Meiborg, and $P$. van der Sijde for the preparation of the micrographs, and Prof. I. Molenaar for his valuable comments.

\section{References}

1. B. D. Ratner, "Biomedical applications of synthetic polymers," in Comprehensive Polymer Science, S. L. Aggarwal (ed.), Pergamon, Oxford, England, 1989, pp. 201-247.

2. M. Spector, C. Cease, and X. Tong-Li, "The local tissue response to biomaterials," Crit. Rev. Biocompatibility, 5, 269-295 (1989).

3. J. Black, "Systemic effects of biomaterials," Biomaterials, 5, 11-18 (1984).

4. H. U. Cameron, R. M. Pilliar, and I. Macnab, "The 
rate of bone ingrowth into porous metal," I. Biomed. Mater. Res., 10, 295-302 (1976).

5. M. Spector, "Historical review of porous coated implants," J. Arthroplasty, 2, 163-177 (1987).

6. B. F. Matlaga, L. P. Yasenchak, and T. N. Salthouse, "Tissue response to implanted polymers: the significance of the shape," J. Biomed. Mater. Res., 10, 391-397 (1976).

7. R. A. White, F. M. Hirose, R. W. Sproat, R. S. Lawrence, and R. J. Nelson, "Histopathologic observations after short-term implantation of two porous elastomers in dogs," Biomaterials, 2, 171-176 (1981).

8. R. E. Baier, "Applied chemistry at protein interfaces," Adv. Chem. Ser., 145, 1-25 (1975).

9. P. B. v. Wachem, T. Beugeling, J. Feijen, A. Bantjes, J. P. Detmers, and W. G. v. Aken, "Interaction of cultured human endothelial cells with polymeric surfaces of different wettabilities," Biomaterials, 6, 403-408 (1985).

10. F. R. Rozema, W. C. de Bruin, R. R. M. Bos, G. Boering, and A. J. Pennings, "Late tissue response to bone-plates and screws of poly(L-lactide) used for fracture fixation of the zygomatic bone plate," Advances in Biomaterials, 10, 349-355 (1992).

11. J. M. Schakenraad, J. A. Oosterbaan, P. Nieuwenhuis, I. Molenaar, J. Olijslager, W. Potman, M. J. D. Eenink, and J. Feijen, "Biodegradable hollow fibres for the controlled release of drugs," Biomaterials, 9, 116-120 (1988).

12. T. Seki, T. Kawaguchi, H. Endoh, K. Ishikawa, K. Juni, and M. Nakano, "Controlled release of 3',5'diester prodrugs of 5-fluoro-2'-deoxyuridine from poly-L-lactic acid microspheres," J. Pharm. Sci., 79, 985-987 (1990).

13. R. K. Kulkarni, K. C. Pani, C. Neuman, and F. Leonard, "Polylactic acid for surgical implants," Arch. Surg., 93, 839-843 (1966).

14. J. Cherfas, "Stretching the point," Science, 247, 630 (1989).

15. S. P. Hertweck, J. A. v. Fraunhofer, and B. J. Masterson, "Tensile characteristics of PTFE sutures," Biomaterials, 9, 457-459 (1988).

16. A. Schindler and D. Harper, "Polylactide. 2. Viscosity-molecular weight relationships and unperturbed chain dimensions," I. Polym. Sci., 17, 2593-2599 (1979).

17. K. H. Lam, P. Nieuwenhuis, I. Molenaar, H. Esselbrugge, J. Feijen, P. J. Dijkstra and J. M. Schakenraad, "Biodegradation of porous versus non-porous poly(L-lactic acid) films," J. Mater. Sci.: Mater. in Med., 5, 181-189 (1994).

18. H. J. Busscher, A. W. J. v. Pelt, H. P. de Jong, and J. Arends, "Effect of spreading pressure on surface free energy determinations by means of contact angle measurements," J. Colloid Interface Sci., 95, 23-27 (1983).

19. E. H. Blaauw, M. F. Jonkman, and P. O. Gerrits, "A rapid connective tissue stain for glycol methacrylate embedded tissue," Acta Morphol. Neerl.-Scand., 25, 167-172 (1987).

20. C. A. Sunderland, W. R. McMaster, and A. F. Williams, "Purification with monoclonal antibody of a predominant leucocyte-common antigen and glycoprotein from rat thymocytes," Eur. I. Immunol., 9, 155159 (1979)

21. H. v. Goor, V. Fidler, J. J. Weening, and J. Grond, "Determinants of focal and segmental glomerulonephritis in the rat after renal ablation. Evidence for in- volvement of macrophages and lipids," Lab. Invest., 64, 754-765 (1991).

22. M. J. Dallman, M. L. Thomas, and J. R. Green, "MRC OX-19: a monoclonal antibody that labels rat $\mathrm{T}$ lymphocytes and augments in vitro proliferative responses," Eur. J. Immunol., 14, 260-267 (1984).

23. G. J. Deenen, S. V. Hunt, and D. Opstelten, "A stathmokinetic study of B lymphocytopoiesis in rat bone marrow: proliferation of cells containing cytoplasmatic $\mu$-chains, terminal deoxynucleotidyl transferase and carrying HIS 24 antigen," J. Immunol., 139, 702-710 (1987)

24. C. D. Dijkstra, E. A. Döpp, P. Joling, and G. Kraal, "The heterogeneity of mononuclear phagocytes in lymphoid organs: distinct macrophage subpopulations in the rat recognized by monoclonal antibodies ED1, ED2 and ED3," Immunology, 54, 589-599 (1985).

25. E. Barbe, J. G. M. C. Damoiseaux, E. A. Döpp, and C. D. Dijkstra, "Characterization and expression of the antigen present on resident rat macrophages recognized by monoclonal antibody ED2," Immunobiology, 182, 88-99 (1990).

26. J. G. M. C. Damoiseaux, E. A. Döpp, and C. D. Dijkstra, "Cellular binding mechanism on rat macrophages for sialylated glycoconjugates, inhibited by the monoclonal antibody ED3," J. Leuckocyte Biol., 49, 434 441 (1991).

27. B. A. Woda, M. L. McFadden, R. M. Welch, and K. M. Bain, "Separation and isolation of rat natural killer (NK) cells from T cells with monoclonal antibodies," J. Immunol., 132, 2183-2184 (1984).

28. R. J. M. Stet, J. Rozing, G. D. Majoor, F. G. M. Kroese, D. Opstelten, and P. Nieuwenhuis, "HIS 19: a monoclonal antibody recognizing a class II polymorphic determinant only absent on RT1n Class II antigens," Transplant. Proc., 17, 1829-1831 (1985).

29. R. S. Cotran and V. Kumar, and S. L. Robbins, "Inflammation and repair," in Pathologic Basis of Disease, R. S. Cotran, V. Kumar, and S. L. Robbins (eds.), Saunders, Philadelphia, PA, 1994, pp. 51-92.

30. P. B. Wachem, M.J. A. v. Luyn, P. Nieuwenhuis, H. K. Koerten, L. Olde Damink, H. Ten Hoopen, and J. Feijen, "In vivo degradation of processed dermal sheep collagen evaluated with transmission electron microscopy," Biomaterials, 12, 215-223 (1991).

31. J. M. Schakenraad, P. Nieuwenhuis, I. Molenaar, J. Helder, P. J. Dijkstra, and J. Feijen, "In vivo and in vitro degradation of glycine/DL-lactic acid copolymers," I. Biomed, Mater. Res., 23, 1271-1288 (1989).

32. M. M. Picken and G. R. Gallo, "Amyloid enhancing factor and inflammatory reaction," Lab. Invest., 63, 586-587 (1990).

33. R. Kisilevski, "Amyloidosis," in Pathology, E. Rubin and J. L. Farber (eds.), Lippincott, Philadelphia, PA, 1994, pp. 1163-1174.

34. S. A. Weitzman and L. I. Gordon, "Inflammation and cancer: role of phagocyte-generated oxidants in carcinogenesis," Blood, 76, 655-663 (1990).

35. T. Nakamura, Y. Shimizu, N. Okumura, T. Matsui, S. H. Hyon, and T. Shimamoto, "Tumorgenicity of poly-L-lactide (PLLA) plates compared with medical grade polyethylene," J. Biomed. Mater. Res., 28, 17-25 (1994).

36. A. Nakamura, Y. Kawasaki, K. Takada, Y. Aida, Y. Kurokama, S. Kojima, H. Shintani, M. Matsui, T. Nohmi, A. Matsuoka, T. Sofuni, M. Kurihara, and N. Miyata, "Difference in tumor incidence and other tissue responses to polyetherurethanes and polydimeth- 
ylsiloxane in long-term subcutaneous implantation into rats," J. Biomed Mater. Res., 26, 631-650 (1992).

37. S. J. Mentzer, D. V. Faller, and S. J. Burakoff, "Interferon- $\gamma$ induction of LFA-1 mediated homotypic adhesion of human monocytes," J. Immunol., 137, 108113 (1986).

38. J. Most, H. P. Neumayer, and M. P. Dierich, "Cytokine-induced generation of multinucleated giant cells in vitro requires interferon- $\gamma$ and expression of LFA1," Eur. J. Immunol., 20, 1661-1667 (1990).

39. L. M. Shaw, J. M. Messier, and A. M. Mercurio, "The activation dependent adhesion of macrophages to laminin involves cytoskeletal anchoring and phosphorylation of the $\alpha_{6} \beta_{1}$ integrin," J. Cell Biol., 110, 2167-2174 (1990).

40. D. E. Ingber and J. Folkman, "Tension and compression as basic determinants of cell form and function: Utilization of a cellular tensegrity mechanism," in Cell Shape: Determinants, Regulation and Regulatory Role, Academic, New York, 1989, pp 3-31.

41. B. Ratner, A. Johnston, and T. Lenk, "Biomaterial surfaces," J. Biomed. Mater. Res., 21, 59-87 (1987).

42. R. Marchant, K. Miller, and J. Anderson. "In vivo biocompatibility studies, $\mathrm{V}$ : in vivo leucocyte interac- tions with Biomer," J. Biomed Mater. Res., 18, 1169 1189 (1988)

43. N. Ziats, K. Miller, and J. Anderson, "In vitro and in vivo interactions of cells with biomaterials," Biomaterials, 6, 396-402 (1988).

44. R. E. Baier, A. E. Meyer, J. R. Natiella, R. R. Natiella, and J. M. Carter, "Surface properties determine bioadhesive outcome: methods and results," 1 . Biomed. Mater. Res., 18, 337-355 (1984).

45. K. M. Miller and J. M. Anderson, "Human monocyte/ macrophage activation and interleukin 1 generation by biomedical polymers," I. Biomed. Mater. Res., 22, 713-731 (1988).

46. K. M. Miller, V. Rose-Caprara, and J. M. Anderson, "Generation of IL-1 like activity in response to biomedical polymer implants: A comparison of in vitro and in vivo models," I. Biomed. Mater. Res., 23, 10071026 (1989).

47. T. J. Krause, F. M. Robertson, J. B. Liesch, A. J. Wasserman, and R.S. Greco, "Differential production of interleukin 1 production on the surface of biomaterials," Arch. Surg., 125, 1158-1160 (1990).

Received December 16, 1992

Accepted February 20, 1995 